\title{
Dietary experience modifies horses' feeding behavior and selection patterns of three macronutrient rich diets ${ }^{1}$
}

\author{
S. E. Redgate, $* 2$ J. J. Cooper, $\uparrow$ S. Hall, $\$$ P. Eady, $\dagger$ and P. A. Harris
}

*School of Animal, Rural and Environmental Sciences, Nottingham Trent University, Southwell, Nottinghamshire, NG25 0QF, UK; †Animal Behaviour, Cognition and Welfare Group, School of Life Sciences, University of Lincoln, Lincoln, LN2 2LG, UK; \$Nutrition Group, WALTHAM Centre for Pet Nutrition, Waltham on the Wolds, Leicestershire, LE14 4RT, UK; and §Equine Studies Group, WALTHAM Centre for Pet Nutrition, Waltham on the Wolds, Leicestershire, LE14 4RT, UK

\begin{abstract}
Choice feeding is often used to investigate an animal's nutritional requirements and dietary preferences. A problem with this approach is that animals with long gut transit times, such as the horse, may find it difficult to associate a chosen food with its nutritional consequence when alternative foods are presented simultaneously. One solution is to present foods singly for a period of time before a simultaneous choice session to allow the development of learned associations. This method was used to determine if horse's voluntary intake and feeding behavior was influenced by the macronutrient composition of the diet. Seven stabled horses, maintained on a low intensity exercise regimen, were allowed, on an ad libitum basis, haylage and 3 isocaloric forage based diets that were rich in 1 of 3 macronutrients (protein, lipid, and hydrolyzable carbohydrate). Initially, diets were presented as a 3-way choice for 5 $\mathrm{d}$ (self-selection a [SSa]), then singly (monadic phase) with exposure to each diet for 2 separate periods of $3 \mathrm{~d}$ each, and finally again as a choice for $5 \mathrm{~d}$ (self-selection $\mathrm{b}$ [SSb]). The total amount of trial diet offered differed with trial phase, with 2 to $2.5 \%$ of BW during SSa and
\end{abstract}

the monadic phase, increasing to ad libitum access during SSb. To control differences in the total amount of trial diet offered, 2 measurements of voluntary intake were taken at 4 and $22 \mathrm{~h}$ postpresentation. Daily macronutrient and energy intakes were estimated from proximate analysis of the trial diets and batches of haylage fed. Feeding behavior was observed over a single 4-h period during both self-selection phases. Horses showed no initial preference after $4 \mathrm{~h}$ for any 1 diet during SSa. Following the monadic phase, horses demonstrated a preference for the protein and hydrolyzable carbohydrate rich diets over the lipid rich diet $(P<0.001)$. Dietary experience modified foraging behavior as the total number of visits to the diets decreased during $\mathrm{SSb}$ $(P<0.005)$. Analysis of 24 -h macronutrient consumption showed that protein and hydrolyzable carbohydrate intake increased during SSb, whereas lipid intake remained constant over both self-selection phases $(P<$ $0.001)$. These data indicate for perhaps the first time that horses can respond to dietary macronutrient content and that single presentations during choice studies facilitates expression of dietary preferences.

Key words: behavior, choice feeding, diet, food preferences, horse, macronutrients

(C) 2014 American Society of Animal Science. All rights reserved.

\section{INTRODUCTION}

It is generally accepted that many species select a

\footnotetext{
${ }^{1}$ The authors are grateful to the Equine Studies Group, WALTHAM Centre for Pet Nutrition (Leicestershire, UK) for funding research. The technical assistance and support from the team at SPILLERS (MARS Horsecare, Milton Keynes, UK) and the statistical advice of G. Gettinby is also gratefully acknowledged.

${ }^{2}$ Corresponding author: sarah.redgate@ntu.ac.uk

Received June 18, 2012.

Accepted January 19, 2014.
}

J. Anim. Sci. 2014.92:1524-1530 doi:10.2527/jas2012-5579

diet through the development of associations between the postingestive consequences of ingestion and a food's sensory characteristics (Provenza, 1995; Duncan and Young, 2002). In the horse, it is, nevertheless, reported that selection and intake is largely based on sensory characteristics, given that nutrient content of single feeds tend to be weak predictors of voluntary intake (Dulphy et al., 1997a; Cuddeford, 2005). However, in studies where choices were offered, horses do show changes in preference as a result of dietary consequences. For example, Cairns et al. (2002) controlled organoleptic characteris- 
tics and found a shift in voluntary intake towards feeds higher in energy over feeds lower in energy. One problem with studies involving the simultaneous presentation of feeds is that the development of learned associations between sensory cues and postingestive consequences may be challenging, particularly in animals such as the horse with long gut transit times (Rose and Kyriazakis, 1991; Cairns et al., 2002). A more effective means of demonstrating dietary preferences is to include a single presentation (monadic phase) of each food over a number of days and then offer individuals a choice (Hewson-Hughes et al., 2011).

The addition of a monadic phase has marked benefits over traditional choice testing (without a training period) as pretrial preferences or biases may be overcome by allowing test animals to experience all of the available treatments and greater opportunity to form associations with the choices and their longer term consequences. The aims of this study were 2-fold: 1) to compare the dietary selection patterns of horses both pre- and postexposure to a monadic training phase and 2) to determine if voluntary intake and feeding behavior were influenced by the macronutrient (protein, hydrolyzable carbohydrate, or lipid) composition of the diet when the energy content was held constant.

\section{MATERIALS AND METHODS}

All methods were approved by the University of Lincoln's ethics committee.

\section{Animals and Management Practices}

Seven horses owned by or loaned to the University of Lincoln's Equestrian Centre (Riseholme Park, Lincoln, UK) took part in the trial during the summer of 2004. Six of the horses were geldings, 5 of which were Thoroughbred type and $1 \mathrm{a} \mathrm{Cob}$, and the seventh horse was a Cleveland Bay $\times$ Warmblood mare. Horses ranged in age between 6 and $20 \mathrm{yr}$ (median age, $16 \mathrm{yr}$ ). All horses were on a routine anthelmintic and dental care program and only horses in good health and dental status were used. At the start of the trial the mean BW of study horses was $623 \pm 24 \mathrm{~kg}$. Before the trial, horses had been turned out to pasture for $4 \mathrm{wk}$.

Horses were housed in individual stables within an American barn (Loddon Stabling, Norwich, UK) and each stable was bedded with wood shavings. With the exception of 1 horse, which showed aggressive behavior towards neighboring horses when fed, horses had visual, auditory, and olfactory access to neighboring conspecifics through metal grills positioned $1.10 \mathrm{~m}$ from the floor. Fresh water was available ad libitum from an automatic drinker in each stable. To ensure that horses received appropriate vitamins and minerals, they received a small meal at 0800 and $1730 \mathrm{~h}$, which consisted of approxi- mately $800 \mathrm{~g}$ of soaked sugarbeet and $400 \mathrm{~g}$ of a chopped forage (Dengie Hi-Fi Lite; Dengie Crops Ltd., Maldon, UK), together with a broad spectrum vitamin and mineral supplement (Equivite Original; MARS Horsecare UK Ltd., Milton Keynes, UK) and an additional supplement of vitamin E and Se (Equivite; MARS Horsecare UK Ltd.) fed to requirements based on BW. Horses received low intensity exercise during all phases of the trial, although the exercise regimen differed according to trial stage. During both of the self-selection phases, horses were walked twice (morning and afternoon) for $40 \mathrm{~min}$ on a mechanical horse walker set at a constant speed. During the monadic phase, horses had access to pasture that had been grazed down before the study. Horses were allowed $1 \mathrm{~h}$ access to the pasture in the morning and 40 min walking on the horse walker in the afternoon. It was a stipulation of the university's ethics committee that horses had $1 \mathrm{~h}$ free exercise out at pasture during the monadic phase. During these turn-out periods, little grazing and mainly locomotor and social behavior were noted.

\section{Study Design}

Trial Diets. The same batch of Timothy hay (Phleum pratense) was used as the base for the 3 mixed forage diets. Additional macronutrient sources were as follows: protein rich diet (10\% hipro soya), hydrolyzable carbohydrate rich $\operatorname{diet}(10 \%$ cracked maize), and lipid rich diet ( $2.4 \%$ soya oil). Diets were formulated to be rich in 1 macronutrient with as large a differentiation between macronutrients as possible without increasing risk of digestive disturbances. The 3 diets were formulated to have similar DE and fermentable fiber content (Table 1). Diets were coated with a molasses and oil based mix (Molashine; United Molasses, London, UK) to reduce the formation of dust during manufacturing.

Diets were presented in large plastic containers, 660 $\mathrm{mm}$ deep and $810 \mathrm{~mm}$ diameter with a $225 \mathrm{~L}$ volume (Aquaflex Tank; Horse Requisites, Newmarket, UK) to prevent spillage. The same container was used for the same diet and all containers were washed and dried daily. Horses were introduced to the main dietary components gradually over a 14-d period using an adaptation diet consisting of equal proportions of the 3 trial diets. The aim of the adaptation period was to ensure that horses were receiving the ad libitum trial diet before the main data collection phase. However, horses adjusted to the adaptation diet slowly and because of the perceived potential risk of gastrointestinal disturbances, the target intake for this diet after $14 \mathrm{~d}$ introduction was set at 2\% BW along with ad libitum haylage.

Trial Layout. The main data collection period was split into 3 phases of differing time periods: self-selection before experience (self-selection a [SSa]), a monadic phase, and self-selection after the experience (self-selection $b$ [SSb]). The SSa phase consisted of $5 \mathrm{~d}$ access to equal 
Table 1. Nutritional composition of the 3 mixed forage trial diets (DM basis) ${ }^{1}$

\begin{tabular}{lcccc}
\hline \hline Item & Protein rich & CHO-H rich & Lipid rich & Haylage \\
\hline $\mathrm{CP}, \%$ & 11.6 & 9.1 & 8.8 & 9.1 \\
Lipid, \% & 1.9 & 2.2 & 4.3 & 1.7 \\
CHO-H, \% & 10.3 & 13.9 & 8.8 & 7.6 \\
FF, \% & 68.8 & 68.0 & 71.1 & 75.3 \\
DE, MJ/kg & 8.2 & 8.5 & 8.5 & 7.7 \\
\hline
\end{tabular}

${ }^{1} \mathrm{CHO}-\mathrm{H}=$ hydrolyzable carbohydrate; $\mathrm{FF}=$ fermentable fiber.

quantities of all 3 diets. The monadic phase consisted of two 9-d monadic periods (monadic phase 1 and 2). During each 9-d period, horses were fed each diet singly for $3 \mathrm{~d}$. On $\mathrm{d} 3$ of each dietary training period, the next diet was introduced by feeding 50:50 ratio of the current and subsequent diet so as to reduce the risk of gastrointestinal disturbance. The $\mathrm{SSb}$ phase was a repeat of SSa.

Containers were placed at the front of the stable directly on the concrete floor. During the self-selection phases, the position of the 3 containers (each with a different diet) was rotated daily between 3 available positions, so that positional biases could be avoided. It was ensured that horses received each diet at least once in each position over the 5 d. During the monadic phase, the trial diet was placed in 1 container at the front of the stable. Chronological order effects were controlled by ensuring that the sequence that the diets were fed differed between horses.

Quantity of Trial Diet and Forage Fed. Throughout the trial, horses were always provided with ad libitum access to haylage allowing total voluntary intake to be measured. To achieve ad libitum intake on the mixed forage diet, the amount fed varied throughout the different phases of the trial. The total amount of trial diet offered during SSa and the first monadic phase was at $2 \%$ of BW. The total trial diet fed was split 3 ways and equal quantities were added to the 3 containers. During the second monadic phase the quantity of trial diet fed was increased to $2.5 \%$ of BW. For the final self-selection, 6 horses were allowed ad libitum access to the trial diets. Because of concerns that the seventh horse might overeat, this horse remained on a ration of $2.5 \%$ of BW of total trial diet and ad libitum haylage.

\section{Measurements and Sampling}

Voluntary Intake. Each horse's daily intake of the trial diet and haylage was measured using weigh scales (Model FS5Y; HST Scales, Milton Keynes, UK). Two measures of voluntary intake of trial diet were recorded, and the first measurement was taken $4 \mathrm{~h}$ after the initial presentation of diets. Pilot data indicated that $4 \mathrm{~h}$ was sufficient to obtain a measure of choice without horses consuming all of their trial feed (Redgate, 2008). The second measurement was taken the next morning at $22 \mathrm{~h}$ after the initial presentation when horses were taken out for exercise. Measurements of haylage ingestion were taken around the same time as the trial diet at 4 and $24 \mathrm{~h}$ after the initial presentation. At both collections, spilt food from the floor was collected, weighed, and subtracted from the total weight initially presented. Containers were returned to the stable during the horse's morning and afternoon exercise sessions, so as not to disrupt the horse's feeding behavior.

Nutritional Analysis. Samples of the 3 trial diets and the additional haylage were analyzed for nutrient composition (Direct Laboratory Services, Wolverhampton, UK). Values for the 3 macronutrients were calculated from the direct analysis, while the fermentable fiber value was calculated using a modified version of the equation given by Hoffman et al. (2001). Digestible energy was estimated for each food source (Kronfeld, 1996; Harris, 1997). The daily nutrient intakes by individual horses were calculated from the macronutrient values presented in Table 1 and the amount of diet ingested.

Feeding Behavior. Each stable had a low-light intensity black and white video camera (Sanyo B/W CCD Camera; Tracksys, Nottingham, UK) positioned at the back of the stable in the roof. This positioning ensured that the front two-thirds of the stable including the feeding area could be viewed clearly. The feeding behavior of each horse was recorded for a single 4-h period during each self-selection phase. Tapes were analyzed using behavioral analysis software (Observer, version 5, Behavioral Analysis Software; Noldus Information Technology, Wageningen, Netherlands). A continuous sampling method was used to record the duration of each foraging bout from each diet. The horse's feed acquisition and ingestive activities were classed as a single behavioral category of foraging because appetitive and ingestive phases could not be distinguished. Foraging behavior was defined as all occurrences where the horse's head was either in the bucket or subsequently out of the bucket and chewing. The latency to approach each diet from time of presentation (head in bucket) and the frequency of visits to each were also recorded.

\section{Statistical Analysis}

Analysis was performed using the statistical package (Minitab, release 13; Minitab Inc., State College, PA). The diet intake and most behavioral data were normally distributed without need for transformation. Individual GLM factorial ANOVA with 4 factors was used to analyze the voluntary intake of diets at $4 \mathrm{~h}$ after presentation and the total ingestion of macronutrients at 4 and $24 \mathrm{~h}$ after presentation. Phase, diet (macronutrient), and day were fixed factors and horse was a random factor. To determine whether the monadic phase affected voluntary intake and nutrient intake, a phase $\times$ diet (macronutrient) interaction was incorporated into the model. To establish whether intake during each day differed over phases and with different diets (macronutri- 
ents), the interaction terms for phase $\times$ day and day $\times$ diet (macronutrient) were also incorporated into the model. To produce the minimal adequate model interaction, terms that were not statistically significant at $P \leq 0.05$ were excluded (Crawley, 2002). The interaction terms day $\times$ diet and day $\times$ nutrient ( $24 \mathrm{~h}$ after presentation) met this principle and were removed from each model.

Analysis of voluntary intake at $24 \mathrm{~h}$ was not performed due to ceiling effects because of dietary restriction during SSa (Martin and Bateson, 1993). A GLM factorial ANOVA but with 3 factors, phase and day (fixed factors) and horse (a random factor), was used to analyze the total intake of DE. Individual GLM factorial ANOVA but with 3 factors, phase and diet (fixed factors) and horse (a random factor), was used to analyze the time spent foraging and the frequency of visits to the diets. Significance was set to $P \leq$ 0.05 and when appropriate the Bonferroni post hoc test was used to determine any difference between the means of the treatment groups. The requirements of a normal distribution were not met for the latency to approach each diet, and these data were analyzed using a Friedman ANOVA.

Horses consumed all of the trial diet provided during the monadic phase. However, haylage was available ad libitum and a 2-way ANOVA was used to assess whether trial diet or the increase in diet fed during monadic phase 2 influenced the voluntary intake of haylage. Comparisons were not made for the monadic phase due to the increase in trial diet between monadic phase 1 and 2 .

\section{RESULTS}

All horses remained clinically healthy throughout the study. Horse BW remained relatively stable throughout the trial with minimal fluctuations. The mean BW at the start of the trial was $623 \pm 24 \mathrm{~kg}$, and it increased marginally by the final week to $635 \pm 24 \mathrm{~kg}$. Horses consumed the twice daily vitamin and mineral based feeds in their entirety, and these were not considered in the analysis.

\section{Voluntary Intake during the Self-Selection Phases}

The total voluntary intake of trial diet during the initial $4 \mathrm{~h}$ over both self-selection phases was similar (SSa: $4,365 \pm 260 \mathrm{~g} ; \mathrm{SSb}: 5,100 \pm 243 \mathrm{~g}$ ). None of horses finished any of the trial diets during this time period and behavioral observations confirmed that horses did not eat from the haylage nets. The 4-h intakes of each diet were similar during SSa with no overall preferences (Fig. 1). Dietary preferences changed after a period of experience with each diet, as revealed by a phase $\times$ diet interaction $(P$ $<0.001)$. The order of relative preference after a period of experience was protein rich $>$ hydrolyzable carbohydrate rich $>$ lipid rich. The effect of day was found $(P<0.05)$ with the decrease in voluntary intake in $\mathrm{d} 2$ compared with

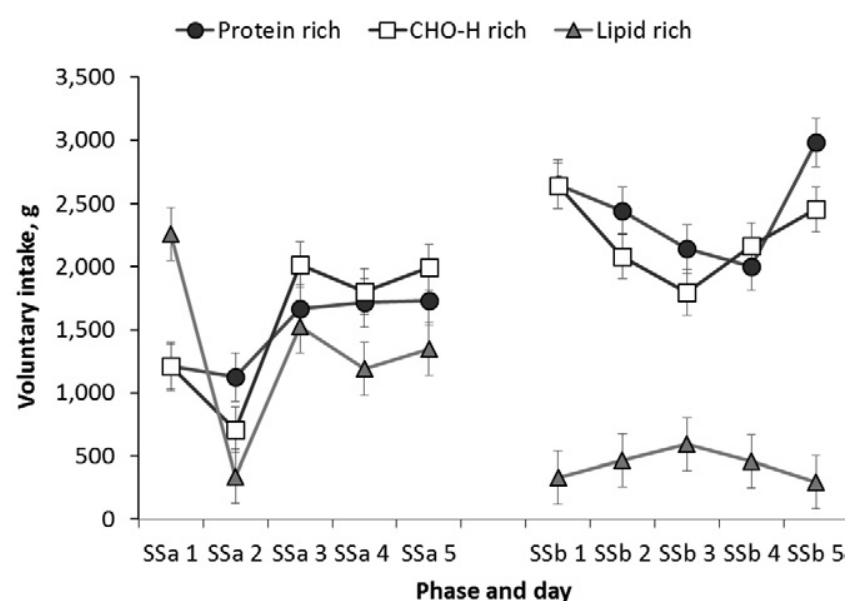

Figure 1. Voluntary intake of 3 macronutrient rich diets after initial $4 \mathrm{~h}$ of presentation to horses over self-selection a (SSa) and self-selection b ( $\mathrm{SSb}$ ). Mean \pm SE, based on 7 horses. Voluntary intake was affected by phase $\times \operatorname{diet}(P$ $<0.001)$ and day $(P<0.05)$. CHO-H $=$ hydrolyzable carbohydrate.

d $5(P<0.001)$. Relative preference of diets followed the same order after $24 \mathrm{~h}$ for both phases (Fig. 2).

\section{Feeding Behavior during the Self-Selection Phases}

Horses spent approximately $3 \mathrm{~h}$ foraging during the 4-h sampling period. The time spent foraging was similar for both of the self-selection phases as well as the duration of foraging on each diet (Table 2). The latency to approach the 3 diets was similar during SSa and SSb. There was no difference between the numbers of occasions horses visited each diet during SSa, but there was a decrease in the total frequency of visits to all diets after a period of experience in $\mathrm{SSb}(P<0.05$; Table 3$)$.

\section{Macronutrient and Energy Intake during the Self-Selection Phases}

The intake of the 3 macronutrients differed at 4 $\mathrm{h}$ (Table 4) and $24 \mathrm{~h}$ (Fig. 3) after presentation. There was a phase $\times$ nutrient interaction $(P<0.001)$ as horses

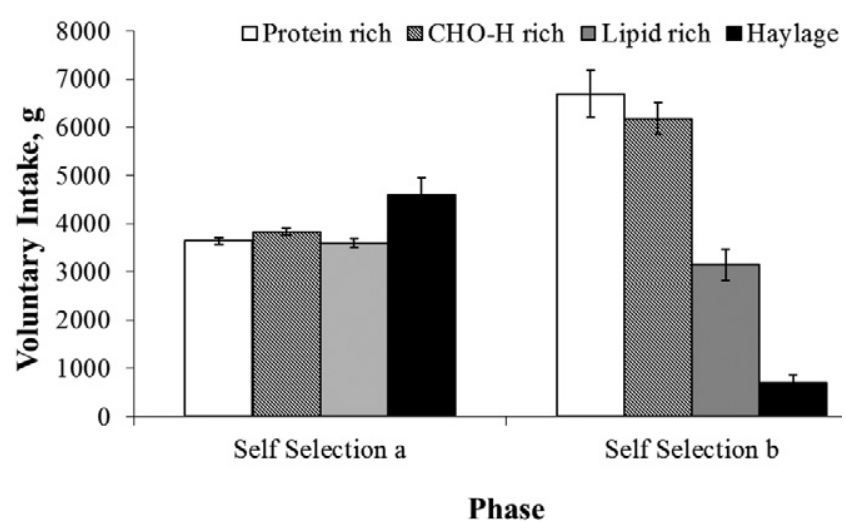

Figure 2. Voluntary intake of 3 macronutrient rich diets and haylage after $24 \mathrm{~h}$ of presentation to horses over self-selection a and self-selection $\mathrm{b}$ $(\mathrm{SSb})$. Mean $\pm \mathrm{SE}$, based on 7 horses. $\mathrm{CHO}-\mathrm{H}=$ hydrolyzable carbohydrate. 
Table 2. Percentage of time spent foraging on each of the 3 macronutrient rich diets over a single 4 -h period during each of the self-selection phases ${ }^{1,2}$

\begin{tabular}{lcccc}
\hline \hline Diet & SSa & SEM & SSb & SEM \\
\hline Protein rich & 34 & 3 & 43 & 14 \\
CHO-H rich & 39 & 5 & 42 & 10 \\
Lipid rich & 27 & 5 & 15 & 5 \\
\hline
\end{tabular}

${ }^{1} \mathrm{SSa}=$ self-selection $\mathrm{a} ; \mathrm{SSb}=$ self-selection $\mathrm{b} ; \mathrm{CHO}-\mathrm{H}=$ hydrolyzable carbohydrate.

${ }^{2}$ Based on 7 horses.

consumed relatively more $\mathrm{CP}$ and hydrolyzable carbohydrate during $\mathrm{SSb}$, whereas lipid intake remained the same over the 2 phases at 4 and $24 \mathrm{~h}$ after presentation. Total macronutrient intake differed between the self-selection phases, with an increase during SSb at 4 and $24 \mathrm{~h}$. At $24 \mathrm{~h}$ after presentation, total macronutrient intake on $\mathrm{d}$ 1 was different from $\mathrm{d} 2$ and $4(P<0.005)$. The daily estimated total DE intake increased from $27.63 \pm 0.79 \mathrm{Mcal}$ during SSa to $29.95 \pm 0.82 \mathrm{Mcal}$ during SSb $(P<0.001)$.

\section{Macronutrient Intake and Haylage Intake during the Monadic Phases}

Macronutrient intakes during the 2 monadic phases are shown in Table 5. Haylage was provided ad libitum and consumption differed according to monadic phase. When the total ration of trial diet increased during the second monadic phase, voluntary haylage intake decreased from $3,590 \pm 296 \mathrm{~g} / \mathrm{d}$ during monadic phase 1 to $1,560 \pm$ $130 \mathrm{~g} / \mathrm{d}$ during monadic phase $2(P<0.001)$. When fed singularly, macronutrient content of the diets did not influence total haylage consumption.

\section{DISCUSSION}

In its natural environment, the horse selects a diet predominantly consisting of grasses and browse species that are seasonally variable in energy density and nutrient content (Tyler, 1972; Duncan, 1992; Fleurance et al., 2001; Menard et al., 2002; Pratt-Phillips et al., 2011). When the nutrient content of the available plant matter declines, the

Table 3. Mean frequency of visits to each macronutrient rich diet over a 4-h period during both self-selection phases $^{1,2}$

\begin{tabular}{llccc}
\hline \hline Diet & SSa & SEM & SSb & SEM \\
\hline Protein rich & 15 & 2 & 12 & 2 \\
CHO-H rich & 15 & 2 & 12 & 3 \\
Lipid rich & 15 & 2 & 7 & 2 \\
\hline \multicolumn{1}{l}{ SSa = self-selection a; $\mathrm{SSb}=$ self-selection $\mathrm{b} ;$ CHO-H = hydrolyzable } \\
carbohydrate. \\
${ }^{2}$ Based on 7 horses. \\
${ }^{3}$ Difference between SSa and SSb, $P<0.05$.
\end{tabular}

Table 4. Nutrient intake after 4-h presentation of the trial diets to horses over both self-selection phases 1,2

\begin{tabular}{llllc}
\hline \hline Macronutrient & SSa & SEM & SSb & SEM \\
\hline $\mathrm{CP}^{3}{ }^{3} \mathrm{~g}$ & 388 & 23 & 472 & 24 \\
$\mathrm{CHO}-\mathrm{H},{ }^{3} \mathrm{~g}$ & 435 & 26 & 537 & 48 \\
Lipid, g & 107 & 7 & 102 & 5 \\
\hline \multicolumn{2}{l}{$\mathrm{SSa}=$ self-selection a; $\mathrm{SSb}=$ self-selection $\mathrm{b} ; \mathrm{CHO}-\mathrm{H}=$ hydrolyzable } \\
carbohydrate. \\
$\quad{ }^{2}$ Based on 7 horses. \\
${ }^{3}$ Difference between SSa and SSb, $P<0.001$.
\end{tabular}

horse alters its selection patterns to increase intake or adopt energy saving strategies such as decreased activity and seeking shelter or both (Gill, 1987; Arnold et al., 2006). This indicates that the horse is sensitive to the changing nutrient or energy content of the available plant matter.

However, a number of studies have failed to show a strong relationship between nutrient content and changes in voluntary intake in the horse (Doreau et al., 1990; Dulphy et al., 1997a, b). Edouard et al. (2008) suggests that this may be due to differences in voluntary intake between horses, as they noted that when individual variation was taken into account, some horses did increase voluntary intake as forage nutrient quality declined. Similarly, Laut et al. (1985) and Cairns et al. (2002) have independently shown that the horse is capable of modifying voluntary intake according to the energy value of the available diets. However, it can take time for an animal to develop an association between what they have eaten and its consequences, especially when multiple feeds are presented (Cairns et al., 2002; Duncan and Young, 2002). The length of this learning period varies across species and is likely to take longer in animals with longer gut transit times (Rose and Kyriazakis, 1991). Indeed, Cairns et al. (2002) found that horses only began to differentiate between 2 feeds of differing energy densities after 10 meals over a 4 - to 5 -d period.

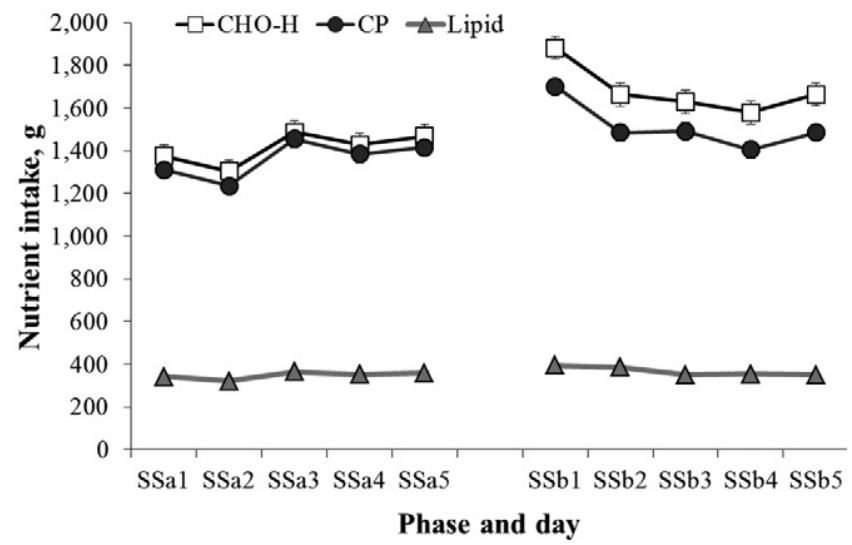

Figure 3. Voluntary intake of macronutrients over a 24-h period during the 5-d self-selection phases. Macronutrient intake was affected by phase $(P<0.001)$, day $(P<0.001)$, and phase $\times$ nutrient $(P<0.001)$. Mean $\pm \mathrm{SE}$, based on 7 horses. $\mathrm{SSa}=$ self-selection $\mathrm{a} ; \mathrm{SSb}=$ self-selection $\mathrm{b} ; \mathrm{CHO}-\mathrm{H}=$ hydrolyzable carbohydrate. 
Table 5. Median intake of the 3 macronutrients when horses were fed the macronutrient rich diets during monadic phases 1 and $2^{1,2}$

\begin{tabular}{|c|c|c|c|c|c|c|}
\hline \multirow[b]{2}{*}{ Macronutrient } & \multicolumn{2}{|c|}{ Protein rich } & \multicolumn{2}{|c|}{$\mathrm{CHO}-\mathrm{H}$ rich } & \multicolumn{2}{|c|}{ Lipid rich } \\
\hline & Monadic 1 & Monadic 2 & Monadic 1 & Monadic 2 & Monadic 1 & Monadic 2 \\
\hline Protein, g/d & $1,438^{3}$ & $1,512^{3}$ & 1,165 & 1,138 & 1,069 & 1,102 \\
\hline Lipid, g/d & 238 & 249 & 274 & 275 & $453^{3}$ & $506^{3}$ \\
\hline
\end{tabular}

In this study, methods that had been used in studies of other species (e.g., Kyriazakis et al., 1988) were adapted to investigate whether horses are capable of changing their dietary preferences according to the macronutrient content of the feed. This approach was designed to overcome 2 problems that may hinder investigations of diet preference when horses are presented with a choice. The first is the inherent dietary preferences or learned associations based on previous experiences that may persist in animals during the trial period (Reed et al., 1992). The second is the long time frames that may be required for animals such as the horse to show adaptive changes in diet (Laut et al., 1985; Cairns et al., 2002). The approach seemed to be successful in that no overall diet preference was found in our study population during the first phase of choice feeding, but following 2 monadic cycles in which diets were presented singularly, there was a marked preference for the hydrolyzable carbohydrate and protein rich diets over the lipid rich diet. These changes in preference following a monadic phase or forced choice (Nicol, 1997) are consistent with other studies, which have adopted the same approach. For example, Kyriazakis et al. (1988) found that a monadic period enhanced dietary learning in pigs, with pigs experiencing a training (monadic) period shifting their selection towards a diet that better met their needs for growth. The influence of the monadic period on the development of dietary association was not evaluated, and this could have been achieved through use of a control group and warrants further investigation for future studies.

Like many herbivores, horses naturally forage from multiple patches (Mayes and Duncan, 1986; Prache et al., 1998) and are generalist, rather than specialist, feeders. For example, out of the 106 species of plants recorded in 1 study area, horses included at least 33 species in their diet (Duncan, 1992). By maintaining this variety, there would, theoretically, be a greater chance of selecting a diet that met certain needs for nutrients (Provenza et al., 1998). Therefore, the sampling behavior displayed by horses in this study may emulate natural foraging patterns or simply be a response to multiple foraging sources (Goodwin et al., 2002). Alternatively, frequent sampling has been identified as a method of evaluating the positive or negative postingestive consequences of feed without overingesting a potentially energy deprived or toxic food (Early and Provenza, 1998; Duncan and Young, 2002). Given that the frequency of visits to all diets reduced after experience, it is plausible that the learned dietary associations can direct foraging behavior.

We acknowledge that one caveat of this study was the presentation of different total amounts of trial diet to horses over the trial phases, and this could have contributed towards the fluctuations in voluntary intake between days. These measures were put in place to safeguard gastrointestinal tract health because horses had not adapted fully to an ad libitum feeding regimen before the start of the trial. It was, therefore, ensured that horses always had access to ad libitum haylage during the trial.

It is of interest to note that despite the change in voluntary intake during the second self-selection phase and preference for the macronutrients protein and hydrolyzable carbohydrate, lipid intake remained consistent across both self-selection phases. Lipid supplementation has been advocated as a means of increasing caloric content of equine feed, as lipids contain proportionally more NE than cereals without carrying the risk of overingestion of high levels of starches and sugars (Kronfeld and Harris, 2003). These data indicate that when given a choice, horses may only include a certain amount of lipid in the diet and will avoid overingesting high-lipid-containing feeds when this limit has been reached. Constraining horses to ad libitum access to a single diet during the monadic phase would have elucidated whether horses were avoiding overconsuming the lipid rich diet. Alternatively, the consistent intake of lipid could have occurred as a result of horses' active selection for an increased hydrolyzable carbohydrate and protein intake during SSb. Both explanations may be related to the proposal that animals may be working towards certain nutrient intake targets by regulating their dietary intake (Staddon, 1983), which has been more recently explored using geometric models to explain nutrient intake patterns when animals are presented with multiple foods that differ in their macronutrient composition (Raubenheimer and Simpson, 1997; Simpson et al., 2003). The apparent preference for deriving energy from protein and carbohydrate sources (over lipids) found in this study could indicate that horses use nutrient intake targets to 
regulate feed intake, and this could be investigated further in the horse under more controlled conditions.

Finally, these approaches offer potential to investigate the ability of horses to alter their diet based on nutrient content and postingestive consequences over pragmatic timescales without long term exposure to choice feeding. In this study, we used diets that differed moderately in macronutrient contents as we did not want to risk health problems associated with overconsumption of specific nutrients, and yet clear preference can be found over relatively short time periods when a period of monadic selection was applied. In conclusion, this study indicated that horses are capable of associating nutrient content with orosensory information at time of ingestion, and the use of monadic phases during test protocols may aid in the development of associations. These approaches may be suitable for testing the capacity of horses to select feeds on the basis of postingestive consequences.

\section{LITERATURE CITED}

Arnold, W., T. Ruf, and R. Kuntz. 2006. Seasonal adjustment of energy budget in a large wild mammal, the Przewalski horse (Equus ferus przewalskii). II. Energy expenditure. J. Exp. Biol. 209:4566-4573

Cairns, M. C., J. J. Cooper, H. P. B. Davidson, and D. S. Mills. 2002. Association in horses of orosensory characteristics of foods with their post-ingestive consequences. Anim. Sci. 75:257-265.

Crawley, M. J. 2002. Statistical computing. An introduction to data analysis using S-plus. John Wiley \& Sons, New York.

Cuddeford, D. 2005. Voluntary food intake by equids. Pferdeheilkunde 21:7-8.

Doreau, M., C. Moretti, and W. Martin-Rosset. 1990. Effect of quality of hay given to mares around foaling on their voluntary intake and foal growth. Ann. Zootech. 39:125-131.

Dulphy, J. P., W. Martin-Rosset, H. P. B. Dubroeucq, J. M. Ballet, A. Detour, and M. Jailler. 1997a. Compared feeding patterns in ad libitum intake of dry forages by horses and sheep. Livest. Prod. Sci. 52:49-56.

Dulphy, J. P., W. Martin-Rosset, H. Dubroeucq, and M. Jailler. 1997b. Evaluation of voluntary intake of forage trough-fed to light horses. Comparison with sheep. Factors of variation and prediction. Livest. Prod. Sci. 52:97-104.

Duncan, A. J., and S. A. Young. 2002. Can goats learn about foods through conditioned food aversions and preferences when multiple food options are simultaneously available? J. Anim. Sci. 80:20912098.

Duncan, P. 1992. Horses and grasses. The nutritional ecology of equids and their impact on the Camargue. Springer-Verlag, New York.

Early, D. M., and F. D. Provenza. 1998. Food flavor and nutritional characteristics alter dynamics of food preference in lambs. J. Anim. Sci. 76:728-734.

Edouard, N., G. Fleurance, W. Martin-Rosset, P. Duncan, J. P. Dulphy, S. Grange, R. Baumont, H. Dubroeucq, F. J. Pérez-Barbería, and I. J. Gordon. 2008. Voluntary intake and digestibility in horses: Effect of forage quality with emphasis on individual variability. Animal 2:1526-1533.

Fleurance, G., P. Duncan, and B. Mallevaud. 2001. Daily intake and the selection of feeding sites by horses in heterogeneous wet grasslands. Anim. Res. 50:149-156.

Gill, E. L. 1987. Factors affecting body condition of new forest ponies. PhD Diss. Univ. of Southampton, Southampton, UK.
Goodwin, D., H. P. B. Davidson, and P. Harris. 2002. Foraging enrichment for stabled horses: Effects on behaviour and selection. Equine Vet. J. 34:686-691.

Harris, P. A. 1997. Energy requirements of the exercising horse. Annu. Rev. Nutr. 17:185-210.

Hewson-Hughes, A. K., V. L. Hewson-Hughes, A. T. Miller, S. R. Hall, S. J. Simpson, and D. Raubenheimer. 2011. Geometric analysis of macronutrient selection in the adult domestic cat, Felis catus. J. Exp. Biol. 214:1039-1051.

Hoffman, R. M., J. A. Wilson, D. S. Kronfeld, W. L. Cooper, L. A. Lawrence, D. Sklan, and P. A. Harris. 2001. Hydrolyzable carbohydrates in pasture, hay, and horse feeds: Direct assay and seasonal variation. J. Anim. Sci. 79:500-506.

Kronfeld, D. S. 1996. Dietary fat affects heat production and other variables of equine performance under hot and humid conditions. Equine Vet. J. Suppl. 22:24-35.

Kronfeld, D. S., and P. A. Harris. 2003. Equine grain-associated disorders. Compend. Contin. Educ. Pract. Vet. 25:974-983.

Kyriazakis, I., G. C. Emmans, and E. C. Whittemore. 1988. The effect of a prior experience of foods on the diets selected by growing pigs. Anim. Prod. 46:523.

Laut, J. E., K. A. Houpt, H. F. Hintz, and T. R. Houpt. 1985. The effects of caloric dilution on meal patterns and food intake of ponies. Physiol. Behav. 35:549-554.

Martin, P., and P. Bateson. 1993. Measuring behaviour. An introductory guide. 2nd ed. Cambridge Univ. Press, Cambridge, UK.

Mayes, E., and P. Duncan. 1986. Temporal patterns of feeding behaviour in free-ranging horses. Behaviour 96:105-129.

Menard, C., P. Duncan, G. Fleurance, J. Georges, and M. Lila. 2002. Comparative foraging and nutrition of horses and cattle in European wetlands. J. Appl. Ecol. 39:120-133.

Nicol, C. J. 1997. Environmental choices of farm animals. In: J. M. Forbes, editor, Animal choices. British Society of Animal Science (BSAS) Occasional Publication, Penucuik, Scotland. p. 35-43.

Prache, S., I. J. Gordon, and A. J. Rook. 1998. Foraging behaviour and diet selection in domestic herbivores. Ann. Zootech. 47:335-345.

Pratt-Phillips, S. E., S. Stuska, H. L. Beveridge, and M. Yoder. 2011. Nutritional quality of forages consumed by feral horses: The horses of Shackleford Banks. J. Equine Vet. Sci. 31:640-644.

Provenza, F. D. 1995. Postingestive feedback as an elementary determinant of food preference and intake in ruminants. J. Range Manage. 48:2-17.

Provenza, F. D., J. J. Villalba, C. D. Cheney, and S. J. Werner. 1998. Self-organization of foraging behaviour: From simplicity to complexity without goals. Nutr. Res. Rev. 11:199-222.

Raubenheimer, D., and S. J. Simpson. 1997. Integrative models of nutrient balancing: Application to insects and vertebrates. Nutr. Res. Rev. 10:151-179.

Redgate, S. E. 2008. Choice feeding and nutritional sense in the domestic horse (Equus caballus). PhD Diss. Univ. of Lincoln, Lincoln, UK.

Reed, D. R., M. I. Friedman, and M. G. Tordoff. 1992. Experience with a macronutrient source influences subsequent macronutrient selection. Appetite 18:223-232.

Rose, S. P., and I. Kyriazakis. 1991. Diet selection of pigs and poultry. Proc. Nutr. Soc. 50:87-98.

Simpson, S. J., R. Batley, and D. Raubenheimer. 2003. Geometric analysis of macronutrient intake in humans: The power of protein? Appetite 41:123-140.

Staddon, J. E. R. 1983. Adaptive behaviour and learning. Cambridge Univ. Press, Cambridge, UK.

Tyler, S. J. 1972. The behaviour and social organization of the New Forest ponies. Anim. Behav. Monog. 5:87-196. 